\title{
Genotype $\times$ Environment Interaction and Stability Analysis for Grain Yield of Mid-hill Rice Genotypes
}

\author{
Hari K. Upreti ${ }^{1}$, Sudarshan Bista ${ }^{1}$, Surya N. Sah ${ }^{2}$ and Ramesh Dhakal ${ }^{3}$ \\ ${ }^{1}$ Agriculture Botany Division-NARC Khumaltar $<$ hari upreti@yahoo.co.in $>$ \\ ${ }^{2}$ ARS-NARC, Pakhribas \\ ${ }^{3}$ ARS-NARC, Dailekh
}

\begin{abstract}
Genotype $\mathrm{x}$ Environment interaction limits the effectiveness of selection when selection is based only on mean yield. This $\mathrm{G} \times \mathrm{E}$ interaction was studied for grain yield in 7 genotypes of mid-hill rice in five different environments across the Nepal. Significant difference was observed among genotype $(\mathrm{G})$, environment $(\mathrm{E})$ and interaction $(\mathrm{G} \times \mathrm{E})$ but could not identify the stable high yielding genotypes for diverse environments. Therefore, stability parameters were calculated and analyzed. On the basis of stability parameters, two genotypes, NR 10414, NR 10492 and NR 10515 were found to be most stable over different environments. NR 10353 was identified as suitable genotypes with high grain yield for favorable environment.
\end{abstract}

Key words: $\mathrm{G} \times \mathrm{E}$ interaction, grain yield, mid-hill rice, stability

\section{INTRODUCTION}

Rice is the main stay of Nepalese farmers and prefers to grow whenever possible. Hill rice contributes about $25 \%$ both in area and production (MoAC 2006). Rice yield is very low in this region due to diverse growing conditions in terms of altitude, soil type and depth, rainfall pattern and irrigation facility and input availability and crop management practices. Varietal adaptability to environmental fluctuations is important for the stabilization of crop production both over regions and years (Singh and Narayan 1993). Hence, several potential genotypes have to evaluate at different environments and years before selecting certain desirable genotypes. The relative performance of different genotypes often varies from one environment to another ie genotype environment interaction exist (Rashid et al 2002), and presence of $\mathrm{G} \times \mathrm{E}$ interaction in any genetical study leads to overestimation of genetical and statistical parameters (Sharma 1998) which makes the breeder difficult to decide which genotypes should be selected.

Significant $G \times E$ interaction results from changes in the magnitude of the differences among genotypes in different environments or from changes in relative ranking of the genotypes ie two types of $\mathrm{G} \times \mathrm{E}$ interaction exist (a) a non cross-over $\mathrm{G} \times \mathrm{E}$ interaction, in which the ranking of genotypes remains constant across environments and the interaction is significant because of changes in the magnitude of the response, or (b) a crossover $\mathrm{G} \times \mathrm{E}$ interaction, in which significant changes in rank occurs from one environment to another where one genotype may be chosen for one environment and other genotype for other. Therefore, plant breeders look for non-crossover type of interaction when selecting genotype for wider adaptation (Won et al 1998). The study of $\mathrm{G} \times \mathrm{E}$ interaction provides useful information to identify stable genotypes over a range of environments or specifically adapted to low and high environment (Reddy et al 1998). Testing genotypes at more location is considered important than testing in more years for stability studies (Joshi et al 2003). The present investigation was therefore, under taken to study $\mathrm{G} \times \mathrm{E}$ interaction and stability analysis to identify stable high yielding genotypes over different situations of mid hill areas of Nepal. 


\section{MATERIALS AND METHODS}

Seven rice genotypes including two standard checks (Khumal-4 and Khumal-11) were evaluated in farmers' fields using a farmer as a replication during 2005. These trials were conducted at five locations with two replication in each site in the mid hill areas viz. Dhankuta and Dolakha in eastern, Khumaltar in central, Lamjung in western and Dailekh in mid western part of Nepal. Status and pedigrees of testing materials are given in Table 1 . The plot size was $10 \mathrm{~m}^{2}$ and spacing was 20$\times 15-\mathrm{cm}$. The recommended packages of practices were followed to raise the good crop at all the locations. Although all agro-morphological data were recorded, only the grain yield data is used in this study. Grain yield was recorded on plot basis and converted to ton $\mathrm{a}^{-1}$ before analysis.

Table 1. Status and pedigree of the testing materials

\begin{tabular}{lll}
\hline Genotype & Pedigree & Status \\
\hline NR 10353-8-2-1 & Jumli Marshi / IR 36 & Pipeline \\
NR 10414-34-2-3 & Gyamja / YR 3825-11-3-2-3-1 & Pipeline \\
NR 10492-7-2-2 & IR 36 / Khumal-5 & Pipeline \\
Khumal-4 & IR 28 / Pokhreli Masino & Released \\
NR 10491-57-2-1 & Khumal-4 / NR 10188-7-1 & Pipeline \\
NR 10515-69-1 & Taichung 176 / Yongeng 3 & Pipeline \\
Khumal-11 & Akiyudaka / Barkat & Released \\
\hline
\end{tabular}

\section{Statistical Analysis}

The analysis of variance combine over locations was carried out to detect the differences among genotypes, environments and genotype $\times$ environment interaction using the statistical package MSTATC. Stability parameters were analyzed using Hanson's Composite Parameters of Stability Model (1970). This model is simple and suitable when number of genotypes and environments are small in which genotypic stability (Di) for a genotype is the deviation of its expected yield $\left(E_{i j}\right)$ from its stable yield $\left(\hat{S}_{i j}\right)$.

$$
\begin{aligned}
& \mathrm{Di}=\left[\sum_{j}^{e}\left(\hat{E}_{i j}-\hat{S}_{i j}\right)^{2}\right]^{0.5} \\
& \hat{E}_{\mathrm{ij}}=\left(\mathrm{x}_{\mathrm{ij}}+\mathrm{X}-\mathrm{gi}-\mathrm{y}_{\mathrm{j}}\right) \text { and } \hat{S}_{i j}=\mathrm{bi}\left(\mathrm{y}_{\mathrm{j}}-\mathrm{X}\right)
\end{aligned}
$$

Therefore,

$$
\mathrm{Di}=\sum_{j}^{e}\left(\mathrm{x}_{\mathrm{ij}}+\mathrm{X}-\mathrm{gi}-\mathrm{y}_{\mathrm{j}}\right)-\mathrm{bi}\left(\mathrm{y}_{\mathrm{j}}-\mathrm{X}\right)^{2}
$$

Where,

$\mathrm{x}_{\mathrm{ij}}=$ Mean of the $\mathrm{i}^{\text {th }}$ genotype over replications at the $\mathrm{j}^{\text {th }}$ environment.

gi $=$ Mean of the $i^{\text {th }}$ genotype over replication and over environments.

$\mathrm{y}_{\mathrm{j}}=$ Mean of the $\mathrm{j}^{\text {th }}$ environment over replication and over genotypes.

$\mathrm{X}=$ Experimental mean over all genotypes over replication and over all environment.

$\mathrm{bi}=$ Regression coefficient of $\mathrm{i}^{\mathrm{th}}$ genotype on the environmental index (Ij) as calculated by Eberhart and Russel (1966).

$b i=\sum_{j}^{e} x_{i j} x I_{j} / \sum I_{j}{ }^{2} \quad$ where $I j=$ Environmental index. 


\section{RESULTS AND DISCUSSION}

Analysis of variance combined over environments showed the highly significant differences among genotypes (G), environments (E) and $\mathrm{G} \times \mathrm{E}$ interaction. Mean genotype yield ranged from 4.1 to 5.8 $\mathrm{t} \mathrm{ha}^{-1}$. The highest yielding cultivars were NR 10353, NR 10414, NR 10515 and NR 10492 (Table 2). The environment effects were significant for the grain yield and it was the highest in Khumaltar followed by Dhankuta, Dolakha and the lowest in Lamjung. This indicates that environmental conditions at the testing sites were varied in terms of soil type and depth, altitude, rainfall and other factor affecting the crop yield.

Table 2. Grain yield (t ha $\left.{ }^{-1}\right)$ of tested genotypes in farmer's field trials combined over location, 2005

\begin{tabular}{lrrrrrrr}
\hline Genotype & Dhankuta & Dolakha & Khumaltar & Lamjung & Dailekh & Mean & Di \\
\hline NR 10353-8-2-1 & 5.5 & 4.1 & 9.8 & 5.1 & 4.3 & 5.8 & 3.1 \\
NR 10414-34-2-3 & 4.9 & 5.0 & 7.3 & 4.7 & 4.6 & 5.3 & 2.2 \\
NR 10492-7-2-2 & 5.8 & 3.8 & 6.6 & 4.0 & 4.5 & 4.9 & 2.2 \\
Khumal-4 & 4.3 & 4.2 & 7.4 & 3.8 & 3.3 & 4.6 & 2.6 \\
NR 10491-57-2-1 & 4.4 & 4.5 & 4.4 & 4.1 & 3.4 & 4.1 & 0.9 \\
NR 10515-69-1 & 5.2 & 4.8 & 7.0 & 3.5 & 4.8 & 5.0 & 2.3 \\
Khumal-11 & 5.9 & 3.9 & 7.0 & 1.7 & 4.8 & 4.7 & 3.3 \\
\hline Mean & 5.1 & 4.3 & 7.1 & 3.8 & 4.2 & 4.9 & \\
& Environment & & Genotype & G $\times$ E & CV, \% & & \\
F-test & $* *$ & & $* *$ & $* *$ & 17.26 & & \\
LSD (5\%) & 0.89 & & & & & & \\
\hline
\end{tabular}

**, Highly significant. Di, Genotypic stability.

The significant $\mathrm{G} \times \mathrm{E}$ interaction effect demonstrated that the genotypes responded differently to the variation in the environmental condition of the testing sites and grain yield fluctuated accordingly. This indicates the necessity of multi-location testing of genotypes before recommending for general cultivation. The highest grain yield across the locations was produced by NR 10353 which ranked was first in Khumaltar and Lamjung only. NR 10414 gave the highest grain yield of $5.0 \mathrm{t} \mathrm{ha}^{-1}$ in Dolakha which was at par with NR 10353 across the locations. Similarly, Khumal-11 ranked first in Dhankuta and gave the lowest yield in Dolakha and Lamjung. Likewise, NR 10491 performed average in all the locations but its mean yield across the location was less than grand mean or experimental yield and could not considered as stable variety.

Thus, analyses of variance combine over locations alone unable to give clear concept in identifying stable high yielding genotypes across the locations. Hence, stability parameters in addition to mean grain yield over location were calculated.

The ideal genotype as proposed by Hanson (cited by Sharma 1998) would have the lowest Di value with higher mean yield than the grand mean. Lower the Di values smaller is the departure from the stable mean. Thus in this study, genotype NR 10491 has the lowest Di (0.9) but its mean yield (gi) was less than experimental yield or grand mean. Therefore, this genotype could not be considered as desire one. In the same line, NR 10414 and NR 10492 showed low Di followed by NR 10515 with higher mean grain yield than the experimental yield. Hence, these genotypes could be considered as stable over the environments and recommended for general cultivation if other parameters of varietal selection favors. However, cultivar NR 10353 with moderately higher genotypic stability (Di of 3.1) with the highest mean yield of $5.8 \mathrm{tha}^{-1}$ could be chosen for favorable environment or high input condition of cultivation.

The results of this investigation demonstrated that the genotypic stability (Di) value with corresponding per se mean performance through light on the relative stability pattern of each genotype. Genotypes NR 10414, NR 10492, and NR 10515 are relatively stable in all location and NR 10353 is suitable in favorable environment. 


\section{REFERENCES}

Joshi BK, KP Shrestha and S Bista. 2003. Yield stability analysis of promising rice genotypes in mid hills of Nepal. In: Proceedings $23^{\text {rd }}$ National summer crops research workshop, NRRP, Hardinath, Dhanusha. Pp 109-116.

MoAC. 2006. Statistical information on Nepalese agriculture 2005/06. Agri-business Promotion and Statistics Division, Ministry of Agriculture and Co-operatives, GON, Singh Durbar, Kathmandu.

Rashid A, G Hazara, N Javed, MS Nawaz and GM Ali. 2002. Genotype x environmental interaction and stability analysis in mustards. Asian Journal of Plant Sciences, 1(5); 591-592.

Reddy JN, D Pani and JK Roy. 1998. Genotype x environment interaction for grain yield of low-land rice cultivars. Indian J. Genet. 58 (2): 209-213.

Sharma JR. 1998. Statistical and biometrical techniques in plant breeding. New Age International Limited publishers, New Delhi.

Singh P and SS Narayan. 1993. Biometrical techniques in plant breeding. Kalyani publishers, New Delhi.

Won JG, T Yoshida and Y Uchimura. 1998. Genotype $\times$ environmental interactions of selected lines in water direct seeded rice. http://www.di.dion.ne.jp. Access 20 September 2005. 